\title{
Exploring the Gap between Museum Policy and Practice: a Comparative analysis of Scottish, English and Welsh Local Authority Museum Services
}

\author{
Vikki McCall* University of Stirling
}

\begin{abstract}
This paper explores the gap between museum policy and practice in the United Kingdom (UK) by offering empirical evidence from a comparative street-level analysis of museum services in Scotland, England and Wales. Exploring devolution in cultural services from the ground-level using Lipsky's (1980) 'streetlevel' approach gives new insights to the role of ground-level workers in cultural policy. It shows that museum workers had an awareness of national policies, but implementation was mainly influenced by a mixture of challenges in the everyday delivery of the museum services studied. Museum workers understood policy as something symbolic rather than relating to action, which reinforced policy distance. Workers at the ground-level had more similarities than differences throughout Scotland, England and Wales and the structural challenges within museum services indicated a complex negotiation that increased agency at the ground-level. These findings outline the potential limitations of written national and international policy in the cultural sector as it is the activities, values and behaviours at the front-line of cultural services that ultimately creates policy in the cultural sector. ${ }^{1}$
\end{abstract}

Key words: Cultural policy; museum workers; UK devolution; policy distance; street-level analysis; Lipsky

\section{Introduction}

The matter of how organizational blueprints are mediated at coalfaces, assembly lines and the front line offices of public services has long been of sociological interest. What is at stake here is, so to speak, the 'cunning of reason', the process by which some kind of order emerges as the word of authority is interpreted across organizational networks. This paper focuses on the difference and the relationship between the language of cultural policy-as-written and the front-line experiences of museum workers. Michael Lipsky's (1980) influential concept of street-level bureaucracy is utilized as a way of theorizing the dynamic negotiation between these two dimensions of modern social life. Front line workers delivering public services, he showed, 'believe themselves to be doing the best they can under adverse circumstances, and they develop techniques to salvage service and decision-making values within the limits imposed upon them by the structure of the work' (Lipsky 2010: xiii). The empirical evidence outlined in the paper offers insights into the nature of cultural policy as it explores the gap between official policy-as-written and the structures around it.

Analyzing cultural services from this perspective is relatively new (McCall 2009; McCall 2013) but is warranted given the increasing 'attachment' of cultural policies to wider social and economic outcomes (Gray 2007) and the social and economic expectations that have been linked to the cultural sector by policy makers (McCall 2010). In addition to this, processes of national devolution within the UK have added a new and complicated dimension to the politics of national culture in Scotland, England and Wales. For example, there has been a National Strategy for museums and galleries developed in both Scotland and Wales (CyMAL 2010; MGS 2012) and a focus on social inclusion and social justice in England (DCMS 2000, 2006). Given these changes, museums and galleries have an analytical significance for (i) the study of how higher-level national policies have been understood by cultural services within Scotland, England and Wales and (ii) the analysis of 'street-level bureaucracy' in this area. 
This paper explores museum workers' perceptions of policy and reflects on the fragmented structures and restraints within the museums services studied. Data were collected by means of a qualitative methodology that included interviews with 'ground-level' workers and direct observation methods within three local authority museum services. The focus on workers followed Lipsky's (1980) approach to the analysis of public service by focusing on the 'streetlevel', thus allowing new insights into the nature of policy in the cultural sector.

\section{Theorizing cultural policy}

The question of what constitutes 'cultural' and indeed 'policy' is much debated, with 'ambiguity being endemic to the sector' (Gray 2014: 1). The ambiguities of cultural policy are particularly evident in relation to cultural industries which, associated with commerce and tarred with the brush of mass culture, can 'sit uneasily within the public policy framework' (Pratt 2005: 31). What has made this picture even more complex is the UK central, devolved and local governments promoting the social role of cultural services, such as museums, by 'attaching' the cultural sector to goals and objectives that are not traditionally 'cultural' in nature (Gray 2007, 2008). Some clear gaps between policy and practice have been noted in regards to social outcomes and objectives (McCall 2009). This can limit joined-up approaches to overcoming local challenges in practice (Gray 2004). Therefore, the rhetorical claims and aspirations (rather than practices), of central and local governments present multiple and challenging expectations of cultural policy and cultural services in the UK.

In respect of museums, these expectations relate to a sector with particularly fragmented administrations and managerial regimes (Gray 2008: 2011). There are also many different types of museums (trust, independent, national, local authority, regimental) that have different governance and funding structures. Further to these different types of structure, there is geographical fragmentation (Gray 2006), which may increase the diversity of these services given that local contexts differ.

In regards to policy, Gray (2004) notes that local level policy has been seen to dominate for local authority funded museum services. This has meant:

needing to pay attention to at least five different central government departments, four separate task forces, and ten 'arm's-length' 'sponsored agencies', as well as at least ten statuary plans and non-statuary ones, alongside the local authority corporate strategy, best value plan, [and] individual service strategies and plans, and more or less anything else up to and including the planning kitchen sink (Gray 2004: 39-40).

The picture for cultural services in a devolved context is therefore anything but clear. There are multiple policy expectations that promote numerous challenges. This includes the fragmented geographical picture of museums and vague, ambiguous policy expectations.

Lipsky's work on street-level services and workers' relationships with the wider structure began in 1969 but was developed in the influential book Street-Level Bureaucracy: Dilemmas of the Individual in Public Services. Published in 1980, an expanded edition was published in 2010 due to high interest in the field in his 'bottom-up', pragmatic approach to the study of policy. He argues that exploring 'street-level bureaucracies', discretion and routines of practice gives the best understanding of the policy process and the reality of service provision. Lipsky gives a clear idea of why ground-level activity becomes policy, as opposed to that handed down by 'top-floor suites of high-ranking administrators' (1980: xii). It is the 'decisions of street-level bureaucrats, the routines they establish, and the devices they invent to cope with uncertainties and work pressures, [which] effectively become the policies they carry out' (Lipsky 2010: ibid).

In researching how policy was perceived in practice, I have applied a Lipskian mode of analysis (1980) so that the paper presents findings from the 'street-level' of three local authority museum services. Taking this approach provides a conceptual framework for understanding this complexity around cultural policy. This difference between policy-as-written and policy-as-action (Lipsky 1980) is used as a frame for this paper. It focuses on the language-based aspects of policy (mainly policy documents in Scotland, England and Wales) and compares such to the perceptions and understandings at the ground-level of museum services. There is an ongoing 
debate and application of Lipsky's approach in order to understand street-level services and workers' behavioural motivations (Meyers and Vorsanger 2003; Marinetto 2011; Evans 2011). Although museums and cultural services were not a part of his original definition of 'streetlevel bureaucracy', his ideas are directly relevant considering the nature of the state funding for some services and the role of public interaction. Furthermore, Lipsky (2010) encourages the wider application and use of his approach to a range of other services, including statutory and non-statutory services delivered by third sector and non-profit organizations (Lipsky 1977; Lipsky and Smith 1990). Lipsky's (1980) perspective is useful and applicable because he gives a framework for thinking about the role and agency of street-level workers within the context of a public service and the structural restraints within in.

His central themes and conclusions concerning resource limitations, ambiguous goals, performance and time constraints are widely applicable to a variety of services. For example, central to his approach is the idea that street-level services generally have 'idealized', complicated, ambiguous and ultimately unmeasurable goals (Lipsky 2010: 40) and this is a widely held criticism in relation to cultural services (Belfiore 2004; Belfiore and Bennett 2007). Indeed, some have seen instrumental cultural policies as 'policies of extinction' (Belfiore 2004: 200). Furthermore, street-level bureaucracies are difficult - if not impossible - to manage (Lipsky 2010: 223) and it has been noted that the cultural sector is almost impossible to manage (Gray 2006).

Lipsky's (2010) insight into the consequences of ambiguous policy goals and manager/ worker relationships are used to structure the findings within the paper. Local authority services are effectively public sector services with workers who interact with users. In this way, museum workers are agents in the policy process driven by their own professional and personal values and experiences (McCall and Gray 2014). The paper utilizes this approach in the context of UK devolution through a comparative analysis of Scotland, England and Wales to try and frame and understand the complexity of cultural policy in the museum sector.

\section{Devolution and the cultural sector}

Before exploring those findings, some background on devolution in the UK and its implications for cultural policy since 1999 is necessary for understanding the complexity and range of activities that are encompassed by cultural policy. The devolved parliaments of Scotland and Wales are empowered to make primary and secondary legislation and policy on the subjects of tourism, sport and heritage in Scotland (Scotland Act 1998) and culture, sport and recreation and tourism in Wales (Government of Wales Act 1998; 2006). In Scotland, England and Wales, policy expectations relating to culture have been closely linked to other social policy outcomes such as health and education. For example, New Labour in England and Scotland linked the cultural sector and specifically museums to the social inclusion agenda (DCMS 2000; McCall 2009).

The Local GovernmentAct (1999) also included proposals for the modernization of local government, affecting the museum sector by committing local authority museums to long-term local policies and to consulting with the community (in Lawley 2003). The notion of economic development was built into New Labour policy for cultural services from 1999 (Oakley 2011: 284). For Scotland, the first National Cultural Strategy, aimed to enhance the:

...quality of life of individuals and communities, promote social inclusion, raise self-esteem and confidence, and widen horizons', which in turn promotes 'human dignity and rights, and the values of democracy, fairness, tolerance, social justice and equality (Scottish Executive 2000: 3, 9).

The strategy incorporated issues of cultural trade, tourism, migration and cultural exchange showing non-cultural expectations of economic outcomes for cultural services. An economic theme also runs through the strategy, with culture being described as 'the common social currency' alongside individual, community and national outcomes for cultural services to fulfil. Since 2007 the SNP minority government in Scotland have married cultural objectives to their economic strategy and national performance framework (Scottish Government, 2007a). Scottish cultural services are responsible for delivering wider public services and reducing inequality (Scottish Government 2008). 
Similarly, the Welsh Assembly Government (WAG), with the coalition between Welsh Labour Party and the nationalist Plaid Cymru, also linked cultural services with economic outcomes. The first cultural policy from the Welsh Assembly Government (WAG), Creative Future: A Cultural Strategy for Wales specifically prioritized integrating cultural policy with other initiatives. Culture was acknowledged as a 'bridge' to the implementation of cross cutting priorities of social inclusion, equal opportunities and sustainable development (WAG 2002: 9). The document aimed to fulfil

...the Welsh Assembly Government's commitment to equality of opportunity for all of the people of Wales. Sporting facilities, arts centres, theatres and recreational facilities should all be accessible to all people regardless of age, religion, language, disability, gender, ethnicity or sexual orientation (WAG 2002: 2).

Later priorities encouraged individual fulfilment, social capital and collective prosperity through cultural services (WAG 2008a). A new settlement in 2011 took away any restrictions on making laws pertaining to the subject areas and enhanced legislating powers to the newly named Welsh Government.

Despite these policy differences, comparative analysis within the different devolved nations in the UK has not been as developed for the cultural sector as it has for other areas of inquiry ${ }^{2}$. Overall, Keating and McEwan (2006: ibid) observed that:

...there is a surprising lack of work on the effects of devolution to regions and nations on the policy process, policy substance and policy outcomes; there is little comparative work on the performance of regional governments.

This may be due to the UK and devolved parliaments operating on an 'arm's length' basis, through a number of 'Non-Departmental Public Bodies' (NDPBs) that are responsible for arts, sport, film and heritage in England, Scotland, Wales and Northern Ireland (that are detailed a little later in the paper).

This has had implications for the policy, politics and governance that have influenced the 'strategic direction' of cultural policy (Scottish Executive 2006) alongside a shift from focusing on the intrinsic value of culture to an instrumental approach to cultural policy (Orr 2008). Indeed, there is a historical dimension to this for 'culture, in short, has been viewed and used as a tool of public policy' since Victorian times (Hamilton and Scullion 2002: 4; see Belfiore and Bennett 2007 for more detail). Furthermore, the rhetoric of instrumentalism often informs what politicians and civil servants have to say about the social and economic outcomes justifying the arts and cultural sector (McCall 2010). However, little is known as to how any divergence in policy between Scotland, England and Wales has been implemented. The post-devolution focus of this paper is important as there have been on-going debates as to the extent to which UK devolution has influenced general social policy change (Mooney et al. 2008). Galloway and Jones (2010) have claimed that Scotland and England have followed a path of convergence in governance and Schlesinger (2009) notes that Scottish Labour had 'imported' New Labour's cultural policies and terminologies 'without altering a comma or full stop' and this was then taken forward largely unaltered by the SNP. The abstracted cultural policy rhetoric from central and devolved governments has remained very similar in its ambitions and ambiguity throughout the post-devolution period for Scotland, England and Wales. However, there has been little comparative research into the devolved UK cultural services and there are of course inherent difficulties in comparing cultural policies due to the fragmented nature of the sector with its local contexts and multiple exogenous influences (Gray 2010; McCall and Gray 2014). However, it has become more important to offer such an analysis as cultural services such as museums have been increasingly linked to key social, economic and political policy agendas as museums have to increasingly justify their use of public funds in a time of increasing cuts.

\section{Policy expectations around museums: a diverging policy process?}

Amajor feature of post-devolution cultural policy documents is their tendency to use wide, general and ambiguous expectations and arguments. Much of this official discourse revolves around the instrumental and idealized nature of the arts debate introduced above and discussed by Gray 
$(2007,2008)$. It is important to examine these aspects as government discourse provides insights into the ideological construction of the state itself (Fairclough 2001). What this suggests is that the documents that are a subject of this paper are framed and targeted with a view to enlisting stakeholders in a governmental vision. The interpretation and negotiation of the language, therefore, is of central importance. Edelman $(1971 ; 1977)$ has stressed the symbolic nature of policy. He also argued that policy is made from the manipulation of language at the top level to frame the political agenda. The gaps between policy and practice with complex concepts such as social inclusion can create confusion and multiple interpretations at the ground-level. What is clear is that front-line workers are situated in complex structures, subject to different barriers and competing expectations (McCall and Gray 2014), but nonetheless have a key role to play in the experiences of users. This complex negotiation includes expectations to generate actionable outcomes such as enhancing 'quality of life', 'pride' and 'confidence' in Scotland, England and Wales.

The Department for Culture, Media and Sport (DCMS) was the first to publish a series of policy documents that were inherently 'instrumental' in that their focus had become much wider in scope than 'traditional' cultural outcomes (Gray 2007). This meant that cultural services are often positioned in relation to, and expected to fulfil, wider outcomes. For example, the Social Exclusion Unit established Policy Action Team 10 in 1998, thus extending the usual remit of social policy to sport and art and their potential contributions to neighbourhood renewal. The DCMS then developed the aim:

to promote the involvement of culture and leisure activities of those at risk of social disadvantage or marginalisation, particularly by virtue of the area they live in; their disability, poverty, age, racial or ethnic origin. To improve the quality of life by these means (DCMS 2000: 7).

Apolicy document, Centresfor Social Change: Museums, Galleries and Archives for All, centred on combating social exclusion, where 'museums, galleries and archives... act as agents of social change in the community, improving the quality of people's lives through their outreach activities' (DCMS 2000: 3). The paper focused on developing access, audiences and finally making museums into agents of social change. This document 'is highly significant since it explicitly acknowledges the notion that museums have an obligation, as well as merely the potential to tackle the symptoms and causes of social exclusion' (Sandell 2003: 57). This document was the first to oblige museums to be socially inclusive and mainstream social inclusion as a social policy priority within cultural policy.

Arguably, the most significant change has been how and where the more recent policies have been created. Between 2010 and 2013, we can see the beginning of a different emphasis in the rhetoric of cultural policy in Scotland, England and Wales. Museums Archives and Libraries Wales (CyMAL) were the first to publish a National Museums Strategy (CyMAL 2010) and outline the strategic priorities for 2010-2015. They published an action plan at the same time and subsequently brought out a baseline document so that the strategy could be tracked (CyMAL 2011).

For Scotland, the most recent cultural policy document emerging directly from the Scottish Government remains the 2008 Culture Delivers document (Scottish Government 2008) and the emphasis has been on other non-government organizations such as Museums Galleries Scotland (MGS) in making and delivering cultural policy. For the museum sector, Going Further: the National Strategy for Scotland's Museums and Galleries and Strategy to Action: A Delivery Plan for Scotland's Museums and Galleries, set out priorities for the museums and galleries sector in Scotland (MGS 2012, 2013).

For England, one of the most significant organizational changes was the abolition in 2012 of the Museums Libraries and Archives Council (MLA) with its functions passing to Arts Council England (ACE). ACE, rather than the UK government, has set out a policy presented as a strategic framework for the arts in England. In Achieving Great Art for Everyone, ACE (2010) set out five goals for the next ten years. The five goals, which include themes of excellence in the arts, equal opportunities, resilience, leadership and environmental sustainability, were reviewed in 2011 to connect the wider strategy to museums, libraries and archives (ACE 2011). 
Despite the lack of a written policy coming directly from central government and an emphasis on policy from arms-length bodies, there has been a high level of political debate and rhetoric within Scotland, England and Wales since 2010. The priorities of philanthropy and private investment have made their way to the top of current department priorities (DCMS 2011). Furthermore, there have been a series of funding cuts that have impacted on the DCMS and its arms-length bodies (Culture Media and Sport Committee 2011). The UK wide impact of this has been reported in the 'Cuts Survey' run by the Museums Association since 2010. The cuts in the museum services income and workforce have been significant with resulting reductions in exhibitions and school visits and controversial plans for selling collections (Museums Association 2014).

Quite significantly, Scotland and Wales could arguably be seen to take opportunities to emphasize any divergence from England. For example, a crucial difference in approach has involved the different government understandings of the value of culture. Maria Millar, the UK Culture Secretary 2012-2014, clearly emphasized the economic impact and importance of culture and the cultural industries:

I come to you today and ask you to help me reframe the argument: to hammer home the value of culture to our economy. I know this will not be to everyone's taste; some simply want money and silence from Government, but in an age of austerity, when times are tough and money is tight, our focus must be on culture's economic impact (Millar 2013).

The Scottish Culture Secretary, Fiona Hyslop (after Millar's speech) offered a different focus and level of commitment:

The Scottish Government already accepts the case for the role of government in supporting the cultural sector. We actively support the case for public subsidy of the arts. We understand that culture and heritage have a value in and of themselves. I don't need or want the culture or heritage sector to make a new economic or social case to justify public support for their work (Hyslop 2013).

Furthermore, the Welsh Government Minister for Culture and Sport, John Griffiths, also outlined his commitment to funding the Welsh cultural sector:

Yes the arts are an engine for growth but I also recognise the wider value of the arts and it's because of this that, even in these challenging times, I will continue to support our arts and culture in Wales (Griffiths 2013).

On this rhetorical level we are now seeing a clear divergence in stated political commitments to the arts and culture between Scotland, England and Wales. Fiona Hyslop has a more deliberative approach in giving social and economic concerns equal air-time. Millar's speech was, and this was done overtly, a speech to convince the cultural sector to make an economic case. In context, this is really a comparison between two political viewpoints on the cultural sector but these key speeches are made more significant due to the lack of written policy agendas in the area of cultural policy. The differences identified here between the speeches and the policies-as-written also highlight difficulties for the cultural sector as expectations are changed and influenced by political agendas. The speeches and policies highlighted show clear ambiguity in the matter of what aspirations cultural services such as museums should be fulfilling.

Taking a Lipskian (1980) approach tells us that high-level policy language is important but it may not relate to what cultural services implement or deliver. Governments can push activities in a certain direction but the cultural sector is inherently difficult to manage (Gray 2008). There are also managerial, professional and hierarchical processes that hinder top-town policy implementation (McCall and Gray 2014). This leaves room for individual actors and other organizations to interpret and implement the policy in different ways (McCall 2013). Sandell (1998: 416) warns that any attempt at tackling social objectives and creating social change through museums will only be marginal. The expectations are so ambiguous and wide-ranging they become unrealistic. This is emphasized by a lack of guidelines and evaluation structure. Given this ambiguity, therefore, the activities, values and behaviours of cultural workers at the 
ground level become increasingly important. The findings reported here point to the complex and mediated character of policy in the cultural sector. Cultural policy does not begin and end with central governments. Rather it is at least in part an emergent property of interactions between workers, their services and the public.

\section{Methods}

The evidence presented here is based on a comparative analysis that was conducted between Scotland, England and Wales. ${ }^{3}$ The field-work was conducted between July 2009 and April 2010, which was prior to the UK Conservative-Liberal Democrat Coalition election in May 2010 and the Conservative victory of 2015. Therefore, the paper does not take account of more recent policy and funding cuts.

A focus on workers at the ground-level is important as their role can be seen as a 'bridge' between the market and consumption of which relationship building is key (Durrer and Miles 2009). Three local authority museum services were studied due to local authority services having clearer comparative characteristics (Stanziola and Mendez-Carajo 2011). This made a multiple-case design for the research (Yin 2003) following other successful case study methods in this area (Wilson and Boyle 2004; Tlilli 2008; McCall 2009). Furthermore this makes the services studied public services in their governance and funding, which relates to the Lypskian approach and focus on public sector workers.

Fieldwork was conducted between July 2009 and April 2010 and the methods used within the three local-authority museum services case studies included observation and interviews. The museum services were selected on the basis that they were unitary local authority museum services, had devolved leisure services while retaining cultural services, had over ten staff or volunteers, had accredited museums and public space for general use by the public. 32 days of observation were conducted, focusing on the interaction of workers and users within all the museums in each local authority service area, which included mainly urban-based museums but also some in rural locations (eight museums in Scotland, five in England and four in Wales). 41 in-depth, semi-structured interviews were conducted with managers (8), retail staff (3), curators (8), security guards (1), customer assistants (7), volunteers (3), education officers (2), outreach officers (5), administrators (2) and gardeners (2) that lasted from 30 minutes to two and a half hours. These roles often overlapped (e.g. security with customer assistance) and an additional 33 unstructured interviews were conducted with museum workers, mostly focusing on those on the ground interacting with visitors with additional roles such as shop assistants and café staff. The discussion guide was structured in a way that asked very wide questions such as 'what current policies are you aware of?'. The data was therefore very participant-led in its content. The interviews were fully transcribed and organized on QSR Nvivo utilizing a grounded theory approach so that the themes were inductive and data-driven. After the main themes were derived, Lipsky's (1980) approach was then applied for further analysis due to the clear connection with the key findings. Workers' roles in the findings have been kept anonymous due to the nature of this small sector - often within a service there is only one worker with a certain job title. The findings, however, do compare the Scottish, Welsh and English workers and their perspectives. Each case study was selected so that the Scottish, English and Welsh areas were similar. This allowed street-level workers' perspectives to be explored comparatively to give some insight to implementation at the ground-level and what this can tell us about cultural policy.

\section{Findings: Comparing policy and practice}

The previous sections have indicated that policies-as-written have been similar in their overall ambiguity in Scotland, England and Wales. However, even if policy discourse is similar, policy regimes can still differ (Alcock 2009). The top-down policies throughout the UK share a lot of similarities, but things may differ when it comes to the delivery of services. The Lypskian approach focuses on the 'interactions between street-level bureaucrats and clients, which often take place behind closed doors and are therefore difficult to monitor' (Marinetto 2011: 1170). 
The findings indicated that there were of course competing understandings of policy at ground-level. Many museum workers discussed clashing expectations in regards to policy. However, this seemed to be based on resource priorities, rather than policy expectations. Indeed, some more senior workers noted that there sometimes was an alignment with national, regional and local policies:

Some of the words are subtly different but essentially you know, the priorities are very very similar... It was led by, you know, what the expectation was of the DCMS and what they wanted out of us as a museums service. Then what we did was move that on in a way that became real for the staff here. Sometimes there is a bit of a gap in policy and reality (Museum Worker 12, England).

As luck would have it with the main priorities of the county being utilising education, regeneration and demographic change they are all things that we feed into anyway. Because with minimum standards for accreditation, care of collections, care of the buildings and access to the public so it all works in together very well (Museum Worker V, Wales).

Evidence shows that in England and Wales some workers saw a certain alignment in expectations of museums. It should be noted, however, that the above participants were senior managers, and therefore had specific positions that included policy development for their respective service. Also, the perceived policy alignment was often described as 'luck' or something to fit activities into, with a noted gap between policy and reality. In other words, the activity on the ground was happening anyway and if they aligned with policy this was more a matter of coincidence. If they didn't the language around those activities was manipulated to fit. Policy, therefore, had its own emergent reality when shaped and implemented in practice.

In Scotland, the majority of museum workers expressed confusion about how they fitted into the Scottish Governments economic agenda.

The Scottish Government doesn't have that; [discussing 'ticking boxes'] it's much woollier really as you have these single outcomes and so on. And when you see the paper there are only two of them that we give thought to and so on. And it's very (makes a sighing noise) woolly (Museum Worker J, Scotland).

There was a distinct difference between the perceptions of Scotland's central government's approach to policy, compared to England and Wales. The Scottish museum workers could not indicate where they were placed within the Scottish Government's policy agenda. The evidence suggests that Scottish workers found it difficult to link to central and local government policy expectations. It should be pointed out, however, that this agenda was relatively new at the time of the fieldwork. ${ }^{4}$

Overall, museum workers' understandings of policy were fragmented, diverse and influenced from multiple levels. This was further highlighted when comparing the Welsh and Scottish case studies. Both Wales and Scotland had devolved government cultural policy aims that were uniquely national in nature (Scottish Government 2008; WAG 2006). There were also more general national priorities, such as regeneration.

For Wales, the local policy initiative (which has to remain anonymous as to not compromise anonymity) was to make the area that the museum service was in one of the best places to visit in the country. This was an overall strategy that the Welsh museum workers (both managers and front-line) understood and supported.

But yes we are supposed to contribute to the regeneration of the whole of Wales. As a place where people want to come and visit, stay locally, spend locally, shop locally and visit local sites and attractions (Museum Worker I, Wales).

So yeah the position of the authority which is something as such that by 2025 , [the area] will be a shining example of the sort of county people can enjoy living in. The priorities at the moment yeah that works for us we feed into that it's not difficult (Museum Worker V, Wales). 
In Scotland, on the other hand, there was no obvious aim, strategy or objective that staff were able to explain or support. Front-line workers in particular had no concept of what the service was working toward in an overall plan focused on economic growth (Scottish Government 2007). This had led to a lot of uncertainty with workers.

But to me the strategy doesn't seem to be linked... As far as having a strategy for museums if it is not linked to great council policy or social departments or libraries it seems to be more fragmented now (Museum Worker G, Scotland).

Although some workers did connect to local government policy, the majority viewed themselves as very disconnected. This is interesting, as Lipsky (2010:45) argues that ambiguity goes hand in hand with goal conflict and contradictory expectations. The idea that the cultural service was being used to increase economic growth and to promote a political agenda was generally rejected as a driver at the ground level. Workers were more likely to connect to local agendas (spend locally, contribute to your area etc.) but national policy was described as very distant to their day-to-day roles. Devolution had had an impact on workers understandings, but the local agenda was much easier to connect to and seen as less conflictual to the everyday activities of the service. Through practices such as this, public workers portray a 'process of simplification when official categories prove inadequate for expeditious work processing, or if they significantly contradict their preferences' (Lipsky 2010: 83). Lipsky's approach shows us that the result is a realignment of routines and decisions that effectively 'becomes' policy through practice. Therefore, through the simplification and contextualization of written national and local government policy cultural workers are at the centre of giving us insight to the nature of cultural policy, which is always in need of translation and practical embedding into context. The importance of the local context to cultural policy

The locality of the museum service area was a key driver for museum workers' understandings. There was a particular example of this in the Welsh case study. There was a perceived duality in Welsh culture between English and Welsh-speaking communities as 'they try to hold on' (Museum worker IX). One museum worker described the English- and Welshspeaking 'parallel communities', even within the museum service itself (field notes, Wales, 25.01.10). There was tension within local communities around language that had caused resentment, distrust and division. According to some workers, the role of the museum was to generate a sense of nationalism and to make all people who live there feel like they belong. Overall, however, the focus of museums and museum workers was very local and also linked to promoting or reflecting identities.

If they know that their family had that kind of background then they can use it to understand about who they are. It's like personal fulfilment I suppose. It's linked to identity (Museum Worker III, Wales).

Only in Wales did workers sometimes reflect national-orientated goals and this focused mostly on language. Museum workers in the Welsh service were united in their support in promoting the Welsh language. This distinction clearly predates devolution in Wales, which questions the extent to which differing policy regimes (especially in the third sector) are due to devolution (Alcock 2009).

On the other hand, the 'Scottish Homecoming' (a year-long agenda to promote Scotland) was, amongst some, a focus for derision.

And I hate the idea that any political party was motivating the museums service in any way. To meet their ends. And I am aware of some people within have strong views that the SNP have been pushing the Scottish agenda... But this is very parochial, and it's something I feel very strongly about that we Scotland fit into the context of Europe and the rest of the world. And we are viewed and as a modern society and the constant harking back to tossing the caber and whisky and tartan is very retrospective and really backwards (Museum Worker G, Scotland).

Promoting nationalist policy was one area where workers at ground-level showed diverse understandings and limited buy-in. Museum workers in Scotland consistently prioritised a local 
focus and giving knowledge about the World (not just their country) to local people. Scottish ground-level workers often challenged and diverted what they saw as political pressures. This is an example of them utilising discretion, which ultimately makes them key policy agents (Lipsky 2010). McCall and Gray (2014) give examples of curators as powerful agents in subverting political expectations by employing discretion that involves interpretation of policy. Museum workers also showed themselves to be quite politically aware, and sensitive to what they saw as political manipulation. Devolution or the impact of it was not mentioned in England and was of much more concern in the Scottish and Welsh case studies. There were also elements of divergence that were more historical, and linking these to devolution is difficult. However, the concerns and priorities of workers in England, Scotland and Wales can be shown to transcend national policy expectations, which can be actively undermined at the ground level in and local concerns prioritised.

\section{Policy as a distant rhetoric}

The previous sections have shown some divergence in museum workers perceptions but these were mostly related to local differentiations rather than national policy expectations. The museum services studied generally showed more similarities than differences between Scotland, England and Wales. There were clear feelings of policy distance throughout Scotland, England and Wales. On the whole, the challenges at the ground-level within each museum were remarkably similar in each local authority service. This paper now highlights some of the cohesive themes from museum workers around their understandings of policy and how this related to their work.

Museum workers often perceived policy to be very distant to their everyday activities. Priorities were seen mostly as a simple narrative, or rhetoric, which workers found difficult to apply to ground-level activities. Policy was described in a way where it almost existed as a separate entity that did not affect workers activities.

I'm quite realistic enough to know that there are people who plan policy and there are people who implement policy. And I think that, well they are not a million miles apart obviously but there is a huge gap, gulf in the middle. People who write policy think 'oh that's my job done. I've written the policy, there its 10,000 words it's done' and it's the same with policy documents from the Scottish Government or from the Council. You're like well, I know the guy doesn't implement the policy as its stated (low, sarcastic tone) but they have a policy. So it's like a tick box mentality really. We have a policy [tick motion with hand] (Museum Worker (MW) A, Scotland).

Policy in the cultural sector is so vague that government policy has often been seen at a discourse level rather than operational (Gray 2006). There are also key professional, hierarchical, managerial and organisational limitations to implementing policy within museums (McCall and Gray 2014). Therefore the symbolic nature of policy was reinforced at a structural level.

The relationship between workers and policy is shown here to have further complexity. This is because for many workers policy was only held as a rhetoric - as mere words, as corporate speak, or management speak or what the council says or as the meaning of bureaucracy itself. Without sustained practice seeking to make such possible, policy does not automatically have a significant impact on practice any more than ground-level creativity filters to the top. Policy failure, however, 'is purely a matter of perception' (Hay 1995: 50) and the perception of failure is simply a matter of narrative. Top-down policy is so vague, it reinforces Edelman's (1971; 1977) observations that policy can be made symbolic; museum workers found it difficult to link to this 'idea' that exists on paper to practice. Policy existed through management narrative and was communicated 'down' a chain. Policy was seen as symbolic of management. The elements that related to any action, therefore, were often lost in this process. By placing policy as a remote narrative, museum workers effectively distanced themselves from central and local government policy expectations. This in turn gave workers more room to interpret and implement activities in alignment to their own expectations, beliefs and professional norms.

Lipsky (2010: 52) notes that when workers actively distance themselves from policy (and therefore performance measures) it is to increase their autonomy and distance from organizational control. Framing policy as a narrative made it easier for workers to disregard 
policy-makers' expectations. Conflictual and ineffective management can increase discretion and the day-to-day power of workers over museum activities (McCall and Gray 2014). This has been a specific theme for local authority museums as policy has been 'more words than deeds' (GLLAM 2000). This distance was even described as a physical feeling, which furthered the distance felt to any national policies linked to devolution:

$$
\begin{aligned}
& \text { VMc: When you think about policy how you do feel? } \\
& \text { (Laughs) 'Gah yuk' (making a noise) like that (laughs) (MW 8, England). } \\
& \text { Don't know really. I think like, it's kind of faraway do you know what I mean? From } \\
& \text { what I am doing. Don't know why (MW X, Wales). }
\end{aligned}
$$

For the majority of participants the very idea of policy elicited negative emotional responses. The structural expectations built around policy were seen to be very distant to these agents. Policy presented an obstacle that museum workers felt they need to work around. Servicelevel workers framed policy-as-written as symbolic in nature, perhaps as a coping strategy that gave them more power over their own roles. This was reinforced by the structural challenges within each service.

\section{Challenges relating to a local authority service}

The relationship that workers had with the local authority service was an important and reoccurring theme. Lipsky (2010) discusses the generally conflictual relationship between street-level workers and management. However, Evans (2011) takes that analysis further and points out that street-level-workers often do not have conflicts with their immediate managers (who are also often seen as service professionals). In the case of these cultural services researched here, there was a complex relationship with managers but expressions of conflict were more often related to the more 'faceless' government body: the local government authority. This was shown to be one of the main barriers between workers and wider policy agendas.

The policy distance that was felt between workers and higher-level expectations was augmented by the immediate challenges of being located within a local authority service. The subjects of managers, local authorities and managerial control were the most popular topics brought up spontaneously by museum workers in Scotland, England and Wales. Newman and Clarke (2014: 154) note that this focus on such managerialism is an overall reflection of the relationship that people have with the state, and note 'such feelings mean that wouldbe rational discussions about the politics of the state often founder in mutual antagonisms, silencings and mis-hearings'. Therefore the experiences related to this relationship are, like the reflection on language, also symbolic.

However, the relationship was also informed by clear restrictions in employing people, budgets and policy development.

Budgets are just pathetic. When I first started here as an assistant curator twenty years ago the amount of money in the section I worked into then was just over a thousand pounds.... The annual budget now is about the same (Museum Worker 11, England).

Bearing in mind the context of the recession in the UK in 2009/10, the topic of budget restraints was unsurprising. However, the tightening of budgets was perceived by the majority of workers as a long-term activity that has affected the services over a longer period of time (which, as it turns out, has happened).

As well as budget constraints, communication was stated as a challenge within the local authority. This was similar in Scotland, England and Wales, especially in regards to policy development and was attributed especially to being within a large local authority organization. Difficulties in communication were often attributed to the large bureaucratic processes that existed within the local authority structure.

... it's also very frustrating very often the treacle that you end up wading about in to get things done (MW 11, England). 
It's very difficult to get things done. And you find it very frustrating and it's like glue, the best way to describe what you have to get through. Before you do anything you need to write reports, and people need to see that it goes to someone else and it goes on and on and on. And at the end of it all you're told there is no funding to do it... it's partly government because the government changes its position and their priorities and these priorities change as well (Museum Worker 13, England).

The above points show that local government systems and communication are viewed as slow and contribute to the distance felt towards high-level policy agendas and documents. These complex relationships augmented the distance felt between museum workers and their governance structures and enabled them to prioritise the local issues and challenges for museum workers at the ground level.

The findings show that museum workers can actively distance themselves from the local authorities that they work for.

... Museums and heritage and culture probably have a bit of an issue as far as local authorities and bodies are concerned... we fit within them but most of the stuff is written as not being a part of the authority (Museum Worker V, Wales). [sic]

The local authority policies written for the museum service placed it as a separate entity from the council. Workers often felt distant from other public services in the local authority.

The structural constraints can be very different between museums (Gray 2012) but each case study showed a distinct distance between workers at the ground-level and the local authority structure that they worked within. Immediate budget and structural concerns were seen as more important that the distant and vague policy agendas from nation and local government. It would be difficult for services to connect to national policies when workers felt they were already marginalised locally. Therefore the structural restraints and perceptions of these also contribute to a symbolic distance between policy-as-written.

Policy, practice and the illusion of national policy divergence

In light of this, the findings ultimately show that some workers were aware of national and local policy expectations and there are some specific differences in their reactions to policy expectations (such as language in Wales). However, local constraints, communication and structural challenges were the overwhelming focus of workers at ground level in regards to their everyday activities. The negotiation between policy and implementation was a site of struggle between workers and the structures that they work within. Front-line workers reinforce the symbolic nature of policy-as-written and the structures of the state. This creates a gap between policy-as-written and policy-as-action (Lipsky 1980). Utilizing Lipsky's approach helps to show that the wide and ambitious cultural policies set out from 1999 are severely limited by the hard reality of severe budget and bureaucratic restraints at the ground-level of service delivery.

In the wider context, this reinforces the idea that any divergence under devolution is only an illusion (Mooney and Poole 2006). Indeed, Galloway and Jones (2010) have argued that Scotland enjoyed more autonomy before devolution and there has been more convergence in arts policy since 1999. These findings show that workers had more in common (in regards to challenges, understandings of policy) than they did dissimilarities in the perceptions and implementation of cultural policy.

Local authority structures were shown as key constraints for divergence and policy implementation. All three case studies had issues around budgets, communications and bureaucracy. Jones and Stewart (2012) have noted a fear that local government problems will continue in the future, with a reduction in local choice, initiatives and innovation. Museum workers actively distanced themselves from these constraining structures to create more room for creativity and discretion at the ground level. Activities such as these enforce the importance of local communities rather than national policies. Museum services are just as likely to diverge from a service in their neighbouring area as a service over the Scottish, English or Welsh border.

Lipsky's (1980) framework gives a clear indication of the consequences of this for the museum sector. Through these actions, ground-level workers are keeping and expand their autonomy, power and discretion (Lipsky 2010). Similarly to Durrer and Miles's (2009) study on cultural intermediaries, this therefore increases the importance of service-level workers in negotiating the experiences of users. 


\section{Conclusion}

In conclusion, cultural policy is complex and the devolved nations of the UK indicate, at a rhetorical level, an increasing divergence in their approach to cultural services, the creation of policy and the institutions that govern it. However, taking a Lypskian approach limits the importance of any rhetorical divergence as it indicates that policy itself is actually created at the ground level by cultural workers. The activities, values, routines and behaviours outlined in the findings reported here show the distance and discretion at the ground-level and the reality of structural limitations faced by service workers. The cultural workers, or cultural intermediaries, at the ground-level are central to negotiating the experiences of museum visitors. Cultural policy, from this viewpoint, is only created at this point of interaction and interpretation of what is written and what is done; this is an unpredictable, highly contingent process that warrants careful analysis.

The findings presented in this article indicate that instead of national divergence, workers at the ground-level of cultural services in fact have very common challenges, values and coping mechanisms. The links between workers and policy-as-written at both a local and national level was tenuous at best, unless they wished to utilize it as a tool to fulfil their own goals and objectives. This paper therefore outlines the potential limitations of written national and international policy in the cultural sector as it is the activities, values and behaviours at the front-line of cultural services that ultimately creates policy in the cultural sector.

Received March $5^{\text {th }} 2015$

Finally accepted January $15^{\text {th }} 2016$

\section{Notes}

1 This work was supported by the ESRC PhD Studentship scheme

2 Such as for example with health or education; see ESRC (2006) report Devolution and Constitutional Change on wider related issues.

3 Northern Ireland was not included in the analysis due to lack of developed cultural policy at the time and different local authority governance systems.

4 The Scottish National Party had only held their minority government since 2007 before the fieldwork was conducted in Scotland in 2009. Accordingly, it is not surprising that the new policy agenda had not been communicated widely to workers.

\section{References}

Alcock, P. (2009) 'Devolution or Divergence? Third sector policy across the UK since 2000', in Lodge, G. and Schmuecker, K. (eds) Devolution in Practice: Public Policy Differences Within the UK. London: IPPR. http://www.birmingham.ac.uk/ generic/tsrc/documents/tsrc/working-papers/briefing-paper-2.pdf (last accessed 14 November 2013).

Arts Council England (ACE) (2010) Achieving Great Art for Everyone. A Strategic Framework for the Arts, http://www.artscouncil.org.uk/publication archive/strategicframework-arts/, (last accessed 8 August 2013)

(2011) Review of the Arts Council's Strategic Framework, London: Arts Council England, http://www.artscouncil.org.uk/media/uploads/pdf/strategic framework review 120711.PDF, (last accessed 6 June 2013)

Belfiore, E. (2004) 'Auditing Culture', International Journal of Cultural Policy, 10 (2) 183-202.

Belfiore, E., \& Bennett, O. (2007) 'Rethinking the Social Impacts of the Arts', International Journal of Cultural Policy, 13 (2) 135-151. 
Cole, M. and Boyne, G. (1996) 'Evaluating the Structure of Local Government: the Importance of Tiers', Public Policy and Administration, 11 (1) 63-73.

Culture, Media and Sport Committee (2011) Funding of the Arts and Heritage: Report, together with formal minutes, London: House of Commons.

DCMS (Department of Culture, Media and Sport) (2000) Centres for Social Change: Museums, Galleries, Archives for All. London: Department of Culture, Media and Sport.

(2006) Understanding the Future: Priorities for England's Museums, London: Department of Culture, Media and Sport, http://www.culture.gov.uk/images/ consultations/cons uf prioritiesforenglandsmuseums.pdf (accessed 15 January 2009).

(2011) Business Plan 2011-2015. http://www.number10.gov.uk/wp-content/uploads/ DCMS-Business-Plan1.pdf (accessed 03 April 2012).

Durrer, V. \& Miles, S. (2009) 'New Perspectives on the Role of Cultural Intermediaries in Social Inclusion in the UK', Consumption Markets and Culture, 12 (3) 225-41.

Edelman, M. (1971) Politics as Symbolic Action, Chicago, III: Markham.

(1977) Political language: Words that Succeed and Politics that Fail, New York: Institute for the Study of Poverty.

ESRC (2006) Devolution and Constitutional Change, http://www.esrc.ac.uk/my-esrc/grants/ RES-219-25-2006/outputs/read/48c31762-1597-474c-bfeb-101442ae276c

Evans, T. (2011) Professional Discretion in Welfare Services: Beyond Street-level Bureaucracy, London: Ashgate.

Fairclough, N. (2001) 'The Discourse of New Labour: Critical Discourse Analysis' in Wetherall, M., Taylor, S. and Yates, S.J. (eds) Discourse as Data: A Guide for Analysis, 229-66, London: Sage Publications.

Galloway, S. \& Jones, H.D. (2010) 'The Scottish Dimension of British arts government: a historical perspective', Cultural Trends, 19 (1-2) 27-40.

GLAM (Group of Large Local Authority Museums) (2000) Museums and Social Inclusion, University of Leicester: Group for Large Local Authority Museums.

Gray, C. (2004) 'Joining-Up or Tagging On?: The Arts, Cultural Policy and the View From Below', Public Policy and Administration, 19 (2) 38-49.

(2006) 'Managing the Unmanageable: the Politics of Cultural Planning'. Public Policy and Administration, (21) 2 101-13.

(2007) 'Commodification and Instrumentality in Cultural Policy'. International Journal of Cultural Policy, 13 (2) 203-13.

(2008) 'Instrumental Policies: Causes, Consequences, Museums and Galleries', Cultural Trends, 17 (4) 209-22.

(2011) 'Museums, Galleries, Politics and Management', Public Policy and Administration, 26, 45-61.

(2014) 'Ambiguity and Cultural Policy', Paper to the International Conference on Cultural Policy Research, Hildesheim, September, 2014. 
Government of Wales Act (2006) http://www.legislation.gov.uk/ukpga/2006/32/contents

Hamilton, C. \& Scullion, A. (2002) 'Cultural Policy and Scotland: Response to the National Cultural Strategy', Scottish Affairs, no. 39.

Hay, C. (1995) 'Structure and Agency' in Marsh, D. and G. Stoker (eds) Theories and Methods in Political Science, 189-206, London: Palgrave/Macmillan.

(1998) 'The Tangled Webs We Weave: the Discourse, Strategy and Practice of Networking', in Marsh, D. (ed) Comparing Policy Networks, Buckingham: Open University Press.

Home Office (2005) Improving Opportunity, Strengthening Society. The Government's strategy to increase race equality and community cohesion. London: Home Office. http://www.homeoffice.gov.uk/documents/improving-opportunity-strat (last accessed 15 January 2009).

Jeffrey, C. (2007) 'The Unfinished Business of Devolution', Public Policy and Administration, 22 (1) 92-108.

Jones, G. \& Stewart, J. (2012) 'Local Government: the Past, the Present and the Future', Public Policy and Administration, 27 (4) 346.

Keating, M. (2006) (ed) Devolution and Public Policy: a Comparative Perspective, London: Routledge.

Keating, M., \& McEwan, N. (2006) 'Introduction: Devolution and Public Policy in Comparative Perspective', in Keating, M. (ed) Devolution and Public Policy, a Comparative Perspective, London: Routledge.

Lawley, I. (2003) 'Local Authority Museums and the Modernizing Government Agenda in England', Museum and Society, 1 (2) 75-86

Lipsky, M. (1977) 'Street-level Bureaucrats and Institutional Innovation: Implementing Special Education Reform', Harvard Educational Review, 47 (2) 171-97.

([1980] 2010) Street-Level Bureaucracy: Dilemmas of the Individual in Public Services. 2nd edition, London: Harvester Wheatsheaf.

Lipsky, M. \& Smith, S.R. (1990) 'Nonprofit Organisations, Government and the Welfare State', Political Science Quarterly, 104 (4) 625-48.

Marinetto, M. (2011) 'A Lipskian Analysis of Child Protection Failures from Victoria Climbie to "Baby P": A Street-Level Re-evaluation of Joined-up Governance', Public Administration, 89 (3) 1164-81.

McCall, V. (2009) 'Social Policy and Cultural Services: A Study of Scottish Border Museums as Implementers of Social Inclusion', Social Policy and Society, 8 (3) 319-31.

(2010) 'Cultural services and Social Policy: Exploring Policy Makers' Perceptions of Culture and Social Inclusion', Journal of Poverty and Social Justice, 18 (2) 169-83.

(2013) 'Citizenship and Museum Workers: a comparative study of Scotland, England and Wales' Engage Journal 32.

McCall, V. \& Gray, C. (2014) Museums and the 'New Museology': Theory, Practice and Organizational Change, Museum Management and Curatorship, 29 (1) 19-35.

Meyers, M.K. \& Vorsanger, S. (2003) 'Street-level Bureaucrats and the Implementation of Public Policy' in Peters, G. B. (ed) Handbook of Public Administration, London: Sage. 
MGS (Museums Galleries Scotland) (2010) Realizing True Impact, Edinburgh: MGS.

(2012) Going Further - the national Strategy for Scotland's Museums and Galleries, http://www.museumsgalleriesscotland.org.uk/research-and-resources/resources/ publications/publication/460/, (last accessed 8 August 2013)

Mooney, G., \& Poole L. (2004) 'A Land of milk and Honey? Social Policy in Scotland After Devolution' Critical Social Policy 24 (4) 458-83.

Mooney, G. Scott, G \& Mulvey, G. (2008) ‘The ‘Celtic Lion' and Social Policy: Some thoughts on the SNP and Social Welfare' Critical Social Policy, 28: 378.

Museums Archives and Libraries Wales (CyMAL) (2010) A Museums Strategy for Wales. Aberystwyth: Welsh Government, http://wales.gov.uk/docs/drah/ publications/100615museumstrategyen.pdf (last accessed 6 June 2013).

(2011) Spotlight on Museums 2011, Aberystwyth: Welsh Government.

Museums Association (2014) Results of Cuts Survey 2014, http://www.

museumsassociation.org/advertise/campaigns/funding-cuts/cuts-survey, accessed 14 October 2015 .

Museums Association Conference (2012). Video: Fiona Hyslop. Available at: http://www. museumsassociation.org/video/21112012-fiona-hyslop-conference-video ,accessed 14 November 2013.

Museums Galleries Scotland (MGS) (2013) From Strategy to Action: A Delivery Plan for Scotland's Museums and Galleries, http://www.museumsgalleriesscotland.org.uk/ research-and-resources/resources/publications/publication/504/from-strategy-toaction-a-delivery-plan-for-scotlands-museums-and-galleries, accessed 8 August 2013/.

Newman, J. \& Clarke, J. (2014) 'States of Imagination', Soundings, 57: 153-169.

Oakley, K. (2011) 'In its own image: New Labour and the Cultural Workforce' Cultural Trends 20 (304) 281-289.

Orr, J. (2008) 'Instrumental or Intrinsic? Cultural policy in Scotland since Devolution', Cultural Trends 17 (4) 309-16.

Pratt, A. (2005) 'Cultural Industries and Public Policy', International Journal of Cultural Policy 11 (1) 31-44.

Robinson, R.C. (2012) 'Funding the 'Nation' in the National Theatre of Scotland' International Journal of Cultural Policy 18 (1) 46-58.

Sandell, R. (2003) 'Social Inclusion, the Museum and the Dynamics of Sectoral Change', Museum and Society 1 (1) 45-62.

Schlesinger, P. (2009) 'The SNP, Cultural Policy and the Idea of the "Creative Economy"' in Hassan, G. (ed.) The Modern SNP: From Protest to Power, 135-46, Edinburgh: Edinburgh University Press..

Scotland Act (1998) http://www.legislation.gov.uk/ukpga/1998/46/contents\#sch5

Scottish Executive (2000) Creating our Future... Minding our Past, Scotland's National Cultural Strategy, Edinburgh: Scottish Government. 
(2006) Draft Culture (Scotland) Bill, Consultation Document, Scottish Executive: Edinburgh.

(2006) Scotland's Culture, Edinburgh: Scottish Executive.

Scottish Government (2007) The Government Economic Strategy. http://www.scotland.gov. uk/Resource/Doc/202993/0054092.pdf, accessed 13 May 2008.

Scottish Government. (2008) Culture: Culture Delivers. Edinburgh. http://www.scotland.gov. uk/Resource/Doc/255857/0075838.pdf accessed 8 January 2009.

Scottish Government. (2013) Scottish Independence Referendum Bill, http://www.scottish. parliament.uk/parliamentarybusiness/Bills/61076.aspx, accessed 21 November 2013.

Scottish Government (2013) Scotland's Future. Your guide to an independent Scotland, Edinburgh, www.scottishreferedum.com accessed 22 January 2014.

Stanziola, J. \& Mendez- Carbajo, D. (2011) ‘Economic growth, government expenditure and income: the case of museums and libraries in England' Cultural Trends 20 (3-4) 243-56.

Tlilli, A. (2008) 'Behind the Policy Mantra of the Inclusive Museum: Receptions of Social "exclusion and inclusion" in Museums and Science Centres' Cultural Sociology 2 (1) 123-47.

WAG. (Welsh Assembly Government) (2002) Creative Future - A Culture Strategy for Wales. Available at: http://wales.gov.uk/topics/cultureandsport/publications/ creativefuture/?lang=en accessed 8 August 2013.

WAG (Welsh Assembly Government) (2007) One Wales: A progressive agenda for the government of Wales. Available at: http://news.bbc.co.uk/1/shared/bsp/hi/ pdfs/27_06_07_onewales.pdf, accessed 21 January 2009.

WAG (Welsh Assembly Government) (2008a) CyMAL: Museums Archives and Libraries Wales, Action Plan 2008-2011. Available at: http://wales.gov.uk/docs//drah/ publications/081208cymalactionplan2008to2011en.pdf?lang=en, accessed 21 January 2009.

WAG (Welsh Assembly Government) (2008b) The Public Value of Learning in Museums, Archives and Libraries - Explaining the Social Generic Outcomes. Available at: http://new.wales.gov.uk/depc/publications/cultureandsport/mal/museum1/resource/ genericsocialoutcomes/The public value of learning.pdf;jsessionid=9JJ8JqnM 9l6Bbbs7r5g6SYz8PLfx5FmYvvmTqps7ZMIPqQVlvQhm!-1335101357?lang=en, accessed 26 February 2009.

Wilson, L.A. \& Boyle, E. (2004) 'The Role of Partnership in the Delivery of Local Government Museum Services: A Case Study from Northern Ireland' The International Journal of Public Sector Management, 17 (6) 531-33.

Yin, R. K. (2003) Case Study Research: Design and Methods. 3rd edn, London: Sage.

*Vikki McCall is a Lecturer in Social Policy and Housing at the University of Stirling. She has previously worked as a researcher for Museums Galleries Scotland trying to increase the quality and value of cultural evidence throughout the museums sector in Scotland. Vikki is also an Associate Lecturer for the Open University and has published work around social policy, social inclusion, museums, policy makers' perceptions of culture and cultural data. 


\section{Address}

School of Social Sciences,

University of Stirling,

Stirling, UK

Room 4S5, Colin bell Building

School of Applied Social Science

University of Stirling

FK9 4LA, UK

Tel: +44 (0) 1786467698

E-mail: vikki.mccall@stir.ac.uk

Twitter: @vikki_mccall 